\title{
An Immunoelectrophoretic Approach to the Identification of Progressive and Fluctuating Isolates of the Hop Wilt Fungus Verticillium albo-atrum
}

\author{
By SUDESH B. MOHAN* AND JON P. RIDE \\ Department of Microbiology, University of Birmingham, P.O. Box 363, \\ Birmingham B15 2TT, U.K.
}

(Received 12 May 1981)

\begin{abstract}
Mycelial and culture filtrate antigens from 10 progressive and 10 fluctuating isolates of Verticillium albo-atrum were analysed by crossed immunoelectrophoresis and rocket-line immunoelectrophoresis using antisera raised against pooled mycelial and pooled culture filtrate antigens from 5 isolates of each type. In crossed immunoelectrophoresis, pooled antigens produced precipitin lines corresponding to about 30 mycelial and 25 culture filtrate antigens with homologous antisera. Cross-absorption of antisera with heterologous antigens indicated that the culture filtrate preparations from the two types of isolate were identical and that the mycelial extracts from the two groups differed in one antigen, antigen ' 21 '. This antigen was present in mycelial preparations from 9 out of 10 progressive isolates but was either absent or present in low concentration in 7 out of 10 fluctuating isolates. Antigen ' 21 ' was also present in culture filtrate preparations from 15 of the 20 isolates.

On the basis of the precipitin patterns of antigen ' 21 ', three serological groups of $V$. albo-atrum may be described. It is suggested that the virulence of progressive isolates might be associated with the production of high concentrations of this antigen.
\end{abstract}

\section{INTRODUCTION}

Vascular wilt of hop (Humulus lupulus), caused by the fungus Verticillium albo-atrum Reinke \& Berthold, was first reported in Britain in 1927 by Harris. Later, Keyworth (1942) and Issac \& Keyworth (1948) identified two types of disease, fluctuating and progressive wilt, attributable to mild (fluctuating) or more virulent (progressive) isolates of the fungus. Fluctuating wilt varies in intensity from year to year, plants rarely dying outright, whereas progressive wilt involves severe effects and can be devastating. In the field, it is not possible to distinguish with certainty between the two types of disease because the symptoms of severe fluctuating wilt may simulate those of progressive wilt. This problem has hindered the eradication programme for progressive wilt, and the disease has spread into all the major hop-growing regions (Sewell \& Wilson, 1964; Sewell, 1975; Ministry of Agriculture, Fisheries \& Food, 1974).

At present the virulence of $V$. albo-atrum isolates can only be assessed by time-consuming pathogenicity tests (Talboys \& Wilson, 1954; Evans \& Framingham, 1979). These take at least three months to complete and only a limited number of isolates can be tested at any one time. Clearly, to control the disease more efficiently and to prevent its further spread, a more rapid method for distinguishing between progressive and fluctuating isolates is required.

Webb et al. (1972) used protein electrophoresis and specific isoenzyme patterns in an attempt to distinguish between the two types of isolate, but failed to detect any differences which could be associated with virulence. It is possible, however, that the differences are reflected in minor protein dissimilarities which could be detected by immunological methods. This paper describes an analysis of mycelial and culture filtrate antigens of progressive and 
fluctuating isolates of $V$. albo-atrum by crossed immunoelectrophoresis and rocket-line immunoelectrophoresis. A subsequent paper will describe results obtained with fluorescent antibody tests using antisera raised against conidia.

\section{METHODS}

Organisms and media. Hop isolates of V. albo-atrum were obtained from the Ministry of Agriculture, Fisheries and Food, South East Region Sub-centre, Olantigh Road, Wye, Kent, U.K. Ten progressive and ten fluctuating isolates were used in this investigation. The original isolate number and the corresponding designations used in the text are summarized in Table 1.

Stock cultures were maintained on $2 \%(\mathrm{w} / \mathrm{v})$ agar slopes prepared from prune extract containing $0.5 \%(\mathrm{w} / \mathrm{v})$ lactose and $0.1 \%(\mathrm{w} / \mathrm{v})$ yeast extract (PLY agar; Talboys, 1960).

Preparation of antigens. Mycelial and culture filtrate antigens were prepared for each isolate from static cultures grown in 21 conical flasks containing $400 \mathrm{ml}$ Vogel's medium (Vogel, 1956) and $2 \%(\mathrm{w} / \mathrm{v})$ sucrose. Flasks were inoculated with conidial suspensions $\left(1 \mathrm{ml} ; 10^{6}\right.$ spores) prepared from washings of 7-d-old PLY agar cultures. After $10 \mathrm{~d}$ in continuous light at $25^{\circ} \mathrm{C}$, the mycelial mat was removed by filtration through a Millipore filter $(5 \mu \mathrm{m}$ pore) and was washed twice with water. The mycelium was resuspended in cold phosphate-buffered saline (PBS; $0.02 \mathrm{M}$-potassium phosphate, $\mathrm{pH} 7.4$, containing $0.15 \mathrm{M}-\mathrm{NaCl}$ and $15 \mathrm{mM}-\mathrm{NaN}_{3}$ ) and homogenized for $3 \mathrm{~min}$ at top speed in a Sorvall Omni-mixer with the barrel immersed in ice. Cell debris was removed by centrifugation $\left(1500 \mathrm{~g}, 10 \mathrm{~min}\right.$ at $\left.4^{\circ} \mathrm{C}\right)$. The supernatant was freeze-dried and dissolved in and dialysed against PBS. Any insoluble material was removed by centrifugation $\left(17000 \mathrm{~g}, 30 \mathrm{~min}\right.$ at $\left.4{ }^{\circ} \mathrm{C}\right)$ and the supernatant was diluted to 5 $\mathrm{mg}$ protein $\mathrm{ml}^{-1}$ with $\mathrm{PBS}$.

For the corresponding culture filtrate preparations, the filtrate was freeze-dried, dialysed and reconstituted to $5 \mathrm{mg}$ protein $\mathrm{ml}^{-1}$ as described above. All antigens were stored at $-20^{\circ} \mathrm{C}$ until required. Protein concentrations were determined by the Lowry method.

Production of antisera. Antisera were raised against mycelial extracts and culture filtrates of the two types of $V$. albo-atrum. Pooled antigens containing equal amounts of proteins from isolates 6 to 10 of each type were used to offset any variations that might occur between isolates of a given type. New Zealand White rabbits ( 2 to $3 \mathrm{~kg}$ each) were immunized by intramuscular injection of $1 \mathrm{ml}$ antigen, emulsified with an equal volume of Freund's incomplete adjuvant, at 14-d intervals for $42 \mathrm{~d}$. A booster injection was given after 6 weeks and the rabbits were bled $10 \mathrm{~d}$ later. The immunoglobulin fractions of the antisera were purified by $\left(\mathrm{NH}_{4}\right)_{2} \mathrm{SO}_{4}$ fractionation and chromatography on DEAE-Sephadex A-50 (Pharmacia) according to the method of Harboe \& Ingild (1973). Purified antisera were concentrated by $\left(\mathrm{NH}_{4}\right)_{2} \mathrm{SO}_{4}$ fractionation, dialysed against $\mathrm{PBS}$ and stored at $4{ }^{\circ} \mathrm{C}$.

Antisera raised against pooled mycelial (pooled PM) and pooled culture filtrate (pooled $\mathrm{PC} / \mathrm{F}$ ) antigens from progressive isolates and against the corresponding antigens (pooled $\mathrm{FM}$ and pooled $\mathrm{FC} / \mathrm{F}$ ) from fluctuating isolates, will be referred to as anti-PM, anti-PC/F, anti-FM and anti-FC/F, respectively.

Cross-absorption of antisera. Purified antisera $(15 \mathrm{ml})$ were mixed with $1 \mathrm{ml}$ of heterologous antigens and incubated at $37^{\circ} \mathrm{C}$ for $30 \mathrm{~min}$ and then at $4{ }^{\circ} \mathrm{C}$ for $20 \mathrm{~h}$. The absorbed antiserum was centrifuged $(12000 \mathrm{~g}, 15$ $\min$ at $4{ }^{\circ} \mathrm{C}$ ) to remove the precipitated antigen-antibody complexes, and the supernatant was reincubated with fresh antigens. This procedure was repeated until no further precipitate appeared.

\section{Table 1. Isolates of Verticillium albo-atrum used in this study}

\begin{tabular}{|c|c|}
\hline \multicolumn{2}{|c|}{ Fluctuating isolates } \\
\hline $\begin{array}{l}\text { Original } \\
\text { isolate no. }\end{array}$ & $\begin{array}{l}\text { Designation } \\
\text { in this study }\end{array}$ \\
\hline $1294 / 911 / 77$ & F1 \\
\hline $1307 / 1088 / 77$ & $\mathrm{~F} 2$ \\
\hline $1326 / 1170 / 77$ & F3 \\
\hline $1348 / 1407 / 77$ & F4 \\
\hline $1350 /$ WM $645 / 77$ & F5 \\
\hline 1459/WM785/78 & F6 \\
\hline $1460 / W M 784 / 78$ & F7 \\
\hline $1447 / 1577(2) / 78$ & F8 \\
\hline $1433 /$ WM769(2)/78 & F9 \\
\hline $1425 /$ WM654/78 & F10 \\
\hline
\end{tabular}

\begin{tabular}{|c|c|}
\hline \multicolumn{2}{|c|}{ Progressive isolates } \\
\hline $\begin{array}{c}\text { Original } \\
\text { isolate no. }\end{array}$ & $\begin{array}{l}\text { Designation } \\
\text { in this study }\end{array}$ \\
\hline $1199 / 988 \mathrm{C} / 77$ & P1 \\
\hline $1312 / 1138 \mathrm{~B} / 77$ & $\mathrm{P} 2$ \\
\hline $1324 / 1172 \mathrm{~B} / 77$ & P3 \\
\hline $1352 / \mathrm{WM} 723 / 77$ & P4 \\
\hline 1352/WM724/77 & P5 \\
\hline 1427/WM697/78 & P6 \\
\hline $1400 / 1074 / 78$ & P7 \\
\hline $1454 / 1599 \mathrm{~A} / 78$ & P8 \\
\hline $1435 / 1400 / 78$ & P9 \\
\hline $1449 / 1578(2) / 78$ & P10 \\
\hline
\end{tabular}


Immunoelectrophoresis. Crossed immunoelectrophoresis (CIE) was performed as described by Weeke (1973) using Litex HSA agarose (Windsor Laboratories). The electrophoresis buffer was $0.02 \mathrm{M}$-barbitone, $\mathrm{pH} 8.6$, containing $1.25 \mathrm{~mm}$-calcium lactate (Laurell, 1965) and $15 \mathrm{~mm}^{-\mathrm{NaN}_{3}}$. A $1 \%(\mathrm{w} / \mathrm{v})$ agarose solution dissolved in the above buffer was poured on to glass plates $(75 \times 50 \mathrm{~mm})$ to give a gel $1 \mathrm{~mm}$ thick. Samples $(10 \mu \mathrm{l})$ were electrophoresed on water-cooled plates at $10 \mathrm{~V} \mathrm{~cm}^{-1}$ for $1 \mathrm{~h}$ in the first dimension, and then at the same field strength for $4 \mathrm{~h}$ in the second dimension in gels containing $50 \mu \mathrm{l}$ antiserum ( $\mathrm{ml}$ agarose $)^{-1}$.

Rocket-line immunoelectrophoresis (RLIE) was as described by Krøll (1973) on glass plates $(100 \times 80 \mathrm{~mm})$. The intermediate gel $(5 \mathrm{~mm}$ wide) contained $200 \mu \mathrm{l}$ antigen and the main gel contained $50 \mu \mathrm{l}$ cross-absorbed antiserum (ml agarose) $)^{-1}$. Samples $(10 \mu \mathrm{l})$ were electrophoresed for $4 \mathrm{~h}$ as described above.

After electrophoresis, the plates were washed in $2 \%(\mathrm{w} / \mathrm{v})$ saline to remove unprecipitated proteins. The plates were dried and stained in $0.5 \%(\mathrm{w} / \mathrm{v})$ Coomassie Brilliant Blue $\mathrm{R}$ in methanol/acetic acid/water $(5: 1: 5$, by vol.) for $5 \mathrm{~min}$ and then destained in dye-free solvent.

\section{RESULTS}

\section{CIE patterns of mycelial and culture filtrate antigens}

The CIE patterns produced by the pooled mycelial antigens from both progressive and fluctuating isolates with their homologous antisera appeared to be similar (Fig. 1a,b). Pooled mycelial antigens from progressive isolates (pooled PM) produced 29 precipitin lines with anti-PM: 27 of these could be traced in the pattern formed by the corresponding antigens from fluctuating isolates (pooled FM) with anti-FM (Fig. 1c, d). Precipitin lines 15 and 21, however, appeared to be missing in gels containing anti-FM and four lines, 30 to 33, in these gels could not be detected in gels containing anti-PM.

Pooled culture filtrate antigens from progressive isolates (pooled $\mathrm{PC} / \mathrm{F}$ ) formed 23 precipitin lines in CIE with anti-PC/F (Fig. $2 a, c$ ). Corresponding lines to most of these antigens could also be traced in the precipitin pattern produced by pooled culture filtrate antigens from fluctuating isolates (pooled $\mathrm{FC} / \mathrm{F}$ ) with anti-FC/F (Fig. $2 b, d$ ), but lines $\mathrm{k}$ to o could not be identified with certainty. With pooled $\mathrm{FC} / \mathrm{F}$, four lines were observed in the region where $\mathrm{k}, 1$ and $\mathrm{m}$ precipitated with pooled $\mathrm{PC} / \mathrm{F}$. One of these lines, therefore, appeared to be specific for pooled FC/F. Lines e?, n?, and o? (Fig. $2 b, d$ ) probably do not correspond to lines e, $\mathrm{n}$ and o (Fig. $2 a, c$ ) because their positions relative to the rest of the precipitin lines were different. In addition, at least three more lines, shown by arrows in Fig. $2 d$, were not detected with pooled $\mathrm{PC} / \mathrm{F}$.

The CIE patterns suggested that there were antigenic differences between the extracts from progressive and fluctuating isolates. Further evidence for these differences was obtained from the CIE patterns produced by culture filtrate antigens with mycelial antisera (Fig. 3). Apparently identical patterns were formed with both pooled $\mathrm{PC} / \mathrm{F}$ and pooled $\mathrm{FC} / \mathrm{F}$ using the two antisera, except for one line, shown by the arrow, which was precipitated by both antigens with anti-PM but not with anti-FM. This indicated that pooled PM contained an antigen which was present in both culture filtrates but not in pooled FM, a result which was confirmed when mycelial antigens were precipitated in culture filtrate antisera (compare Figs $4 a$ and $c$ with Figs $4 b$ and $d$ ). Pooled PM now formed a distinct precipitin line with both antisera which was missing in patterns formed by pooled FM.

\section{Cross-absorption of antisera}

To eliminate some of the inherent difficulties associated with analysing the complex patterns described above, antisera were cross-absorbed with their heterologous antigens to remove common antigens and then tested in CIE with their homologous antigens (Fig. 5). Four precipitin lines, probably corresponding to lines 4, 19, 21 and 22 (cf. Fig. 1c) were obtained with anti-PM absorbed with FM (Fig. $5 a$ ). Similarly, five faint precipitin lines were formed by pooled FM with anti-FM absorbed with PM (Fig. $5 b$ ). The number of precipitin lines produced with anti-PC/F absorbed with $\mathrm{FC} / \mathrm{F}$ and anti-FC/F absorbed with $\mathrm{PC} / \mathrm{F}$ were six and four (Figs $5 c$ and $d$, respectively). These patterns appeared to be specific to each 
(a)

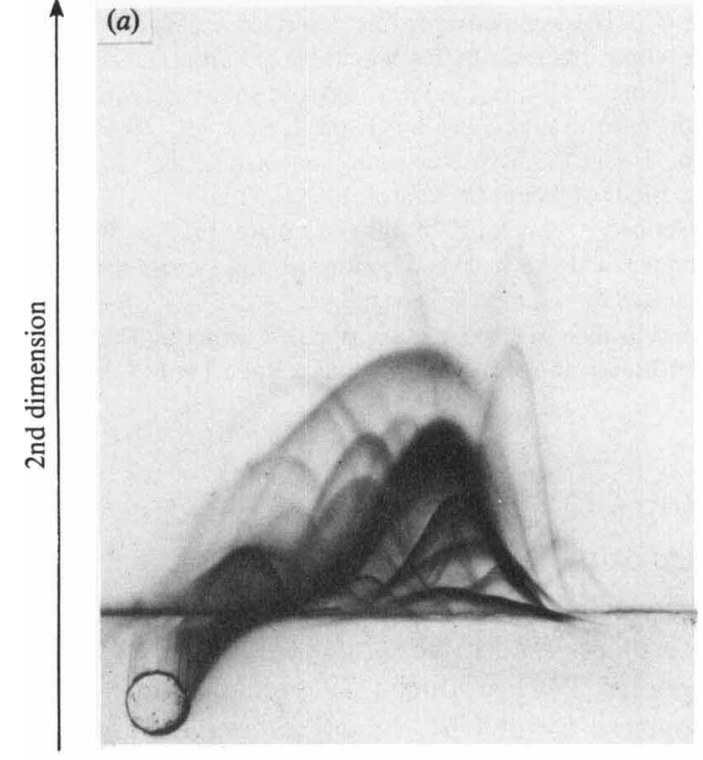

(b)

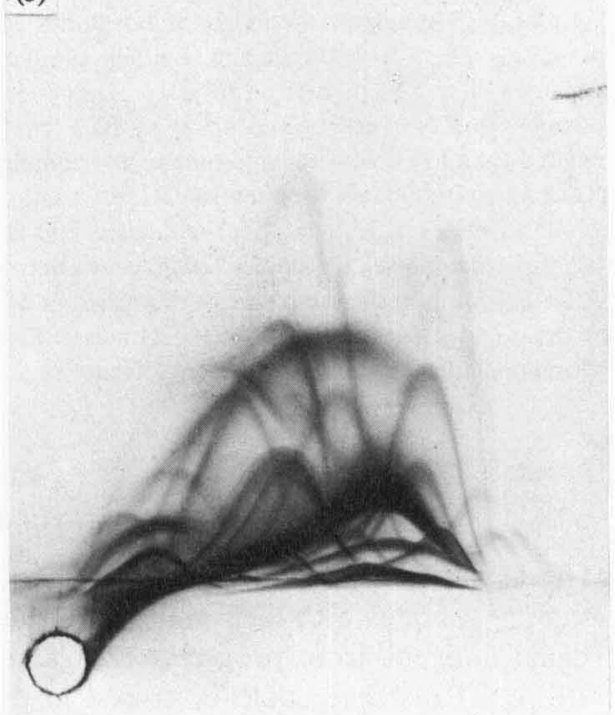

1st dimension
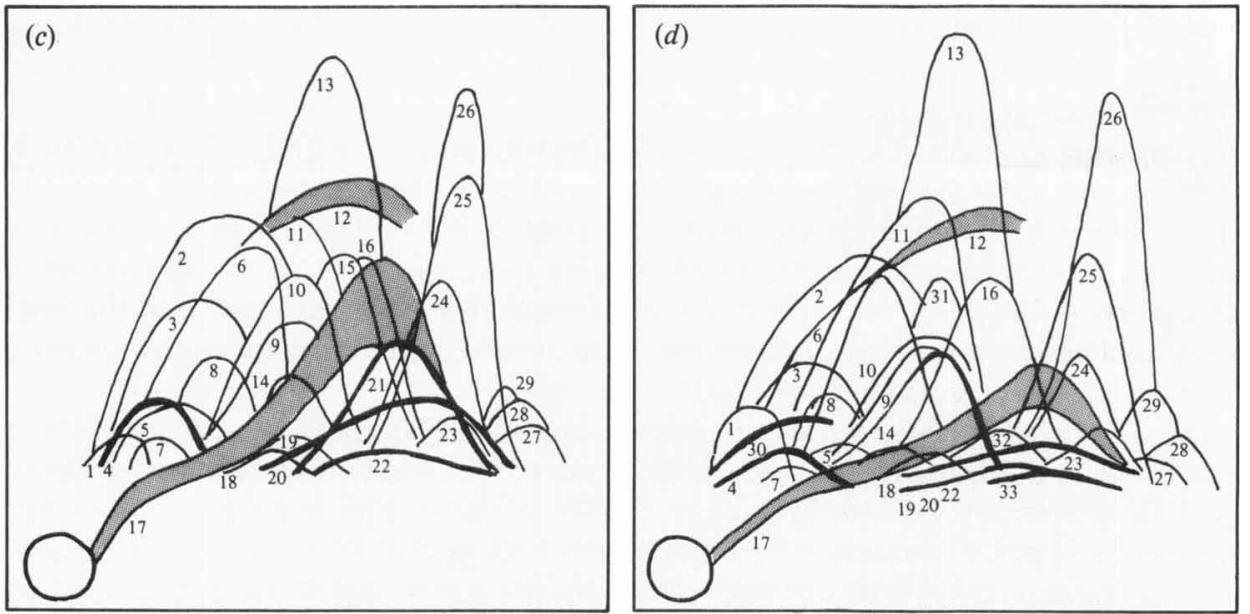

Fig. 1. Crossed immunoelectrophoresis of $V$. albo-atrum mycelial antigens. (a) Pooled PM against anti-PM; (b) pooled FM against anti-FM. (c), (d) Drawings of $(a)$ and $(b)$, respectively, and enumeration of precipitin lines.

antiserum, because further cross-absorption did not change the pattern or the size of precipitin lines formed in CIE. However, in cross-absorption of complex systems, it is difficult to bring all the antigen-antibody systems into the zone of equilibrium or antigen excess simultaneously. It was possible, therefore, that optimum antigen-antibody concentrations for complete absorption were not achieved in spite of serial addition of the antigens.

\section{Analysis of antigens from individual isolates by $R L I E$}

Antigens from the 20 individual isolates were next compared in RLIE in an attempt to resolve the possibility of incomplete absorption of antisera, and also to show whether any of the precipitin lines obtained in CIE with pooled antigens and absorbed antisera could be correlated with virulence. The four absorbed antisera were tested with mycelial and culture 


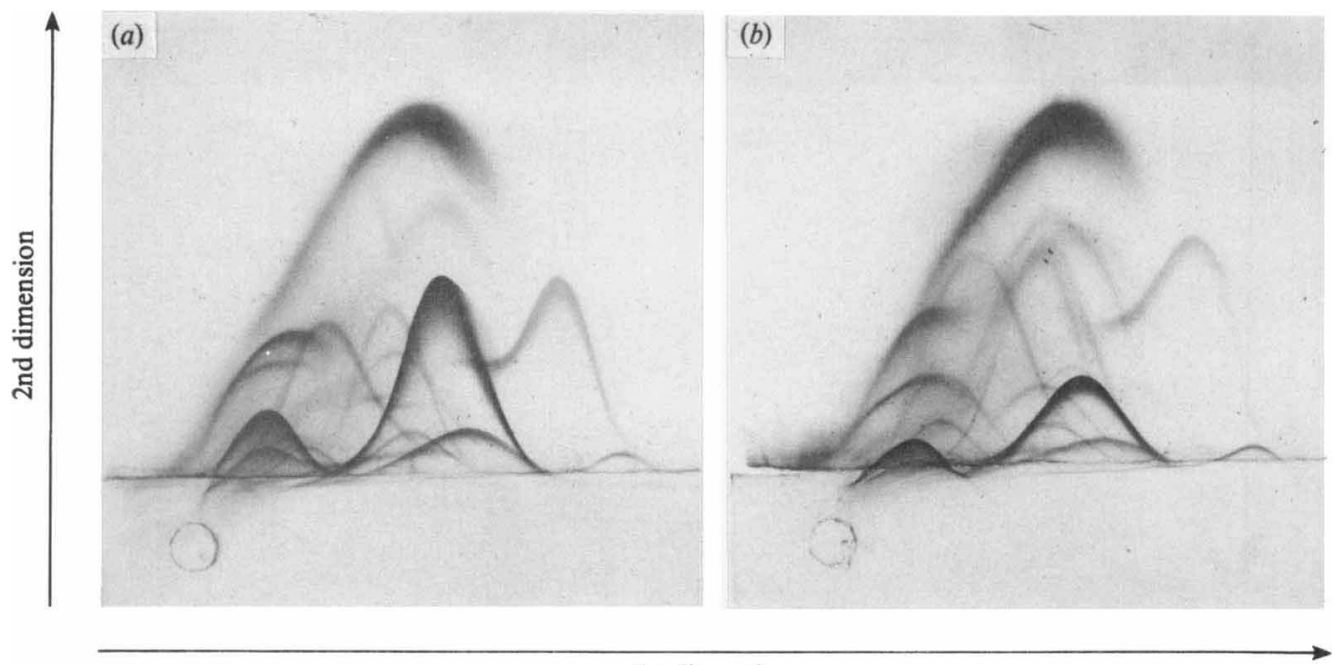

1st dimension
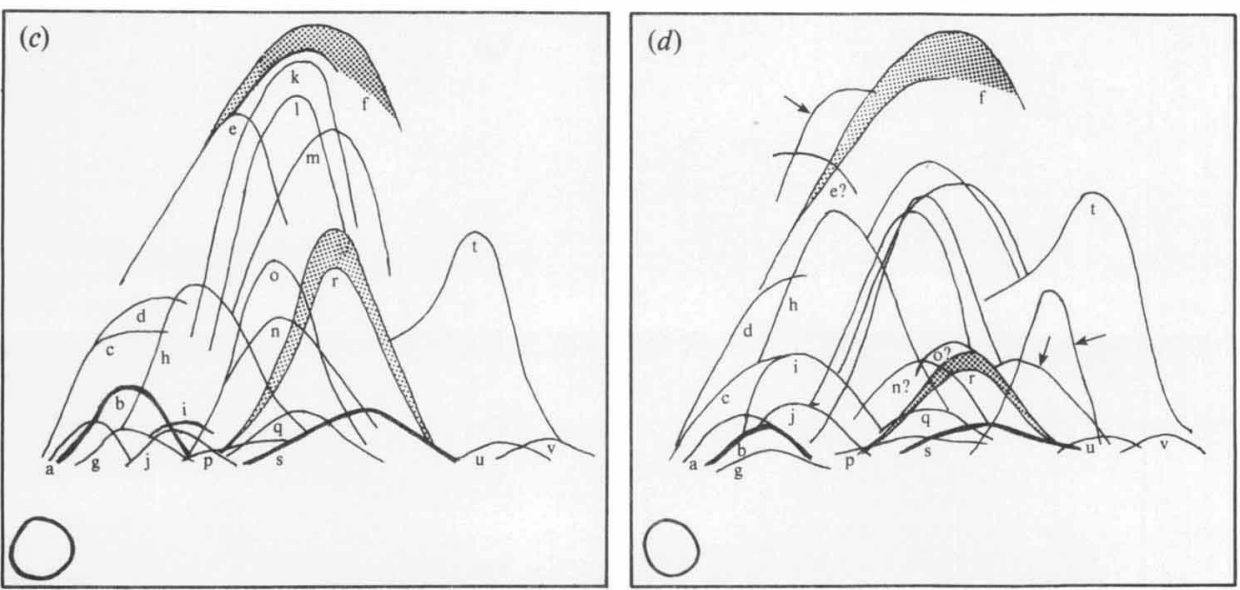

Fig. 2. Crossed immunoelectrophoresis of $V$. albo-atrum culture filtrate antigens. (a) Pooled PC/F against anti-PC/F; $(b)$ pooled FC/F against anti FC/F. (c), (d) Drawings of $(a)$ and $(b)$, respectively, and enumeration of precipitin lines. The arrows in $(d)$ indicate lines not detected with pooled PC/F.

filtrate antigens from both types of isolate. Homologous antigens were placed in the intermediate gels to allow the identification and comparison of antigens from different isolates. The patterns produced by the mycelial or the culture filtrate antigens using absorbed anti-PC/F and anti-FC/F did not show any differences between progressive and fluctuating isolates, suggesting that the culture filtrate antigens from these two groups were identical. In addition, no difference between the two types of isolate could be detected using absorbed anti-FM. With absorbed anti-PM, however, one precipitin line, arrowed in Fig. $6 a$ and probably corresponding to line 21 (cf. Fig. 1c), was present in the mycelial extracts from all progressive isolates except P8. Mycelial antigens from 7 out of the 10 fluctuating isolates formed rockets corresponding to this line (Fig. 6 b). Of these 7, antigens from isolates F7, F8, F9 and F10 formed shorter rockets than the rest. Since equal amounts of protein were applied to each well, the rocket heights indicated the relative concentrations of this antigen ' 21 ' in the various extracts (Laurell, 1966); it was, therefore, present in lower concentrations in the above four isolates and was absent in mycelial antigens from F1, F2 and F5. This variation in 


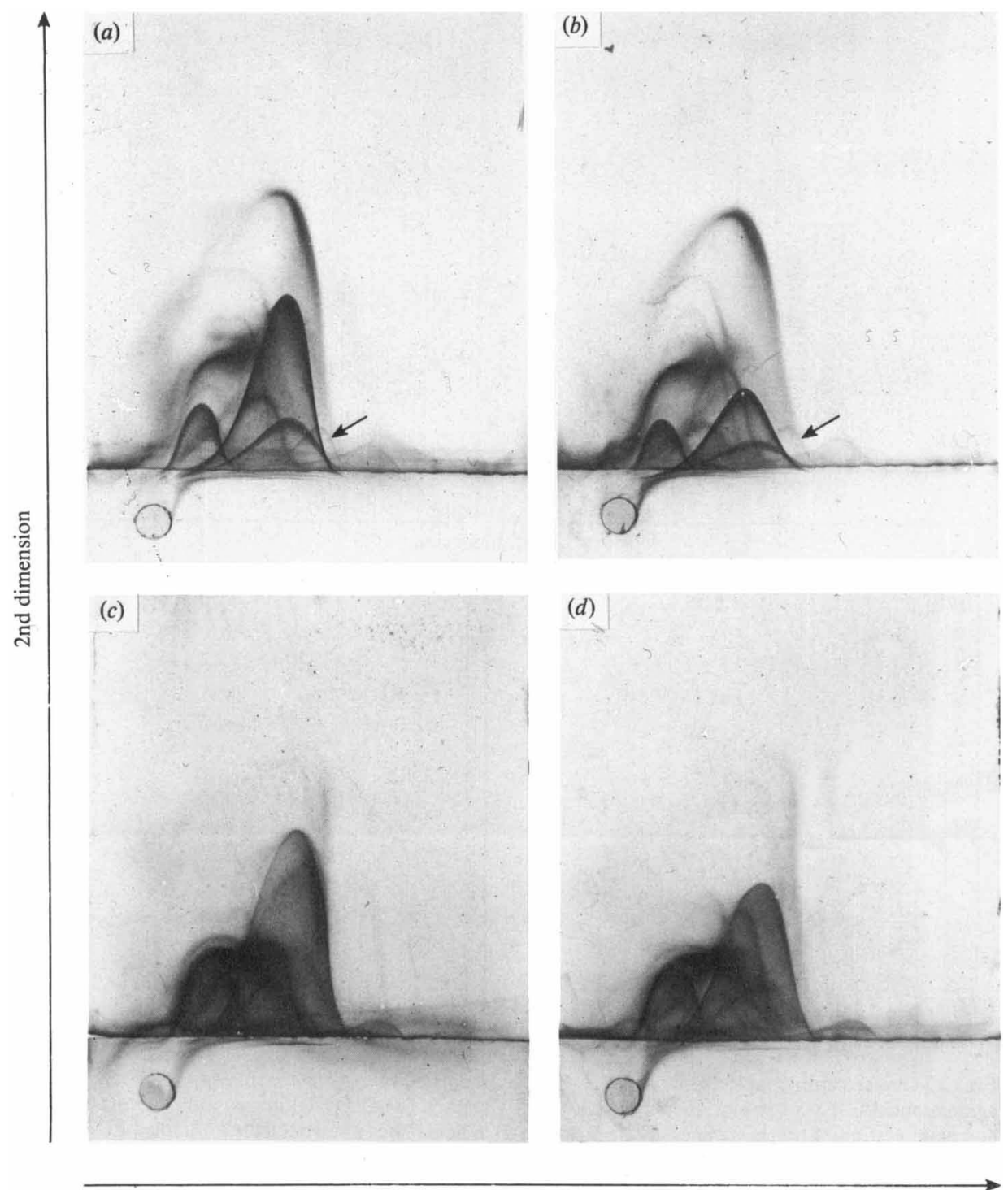

1st dimension

Fig. 3. Crossed immunoelectrophoresis of $V$. albo-atrum culture filtrate antigens against mycelial antisera. (a) Pooled PC/F and (b) pooled FC/F against anti-PM. (c) PC/F and (d) pooled FC/F against anti-FM. The arrows indicate the precipitin line produced with anti-PM but not with anti-FM.

antigen content was also reflected in pooled antigens, the rocket formed with pooled FM being smaller than that obtained with pooled PM (wells $2 \& 1$, respectively, Fig. $6 a, b$ ).

The RLIE patterns obtained with culture filtrate antigens and absorbed anti-PM were similar to those obtained with the mycelial antigens in that one distinct precipitin line was observed with nine progressive isolates (Fig. $6 c$ ). Substantial quantities of this antigen were also present in six fluctuating isolates (Fig. 6d) though in only two (F3 and F6) were the concentrations as high as those observed in progressive isolates. Four of the five isolates in which this antigen was barely detectable (P8, F1, F2 and F5) did not contain the corresponding mycelial antigen. 

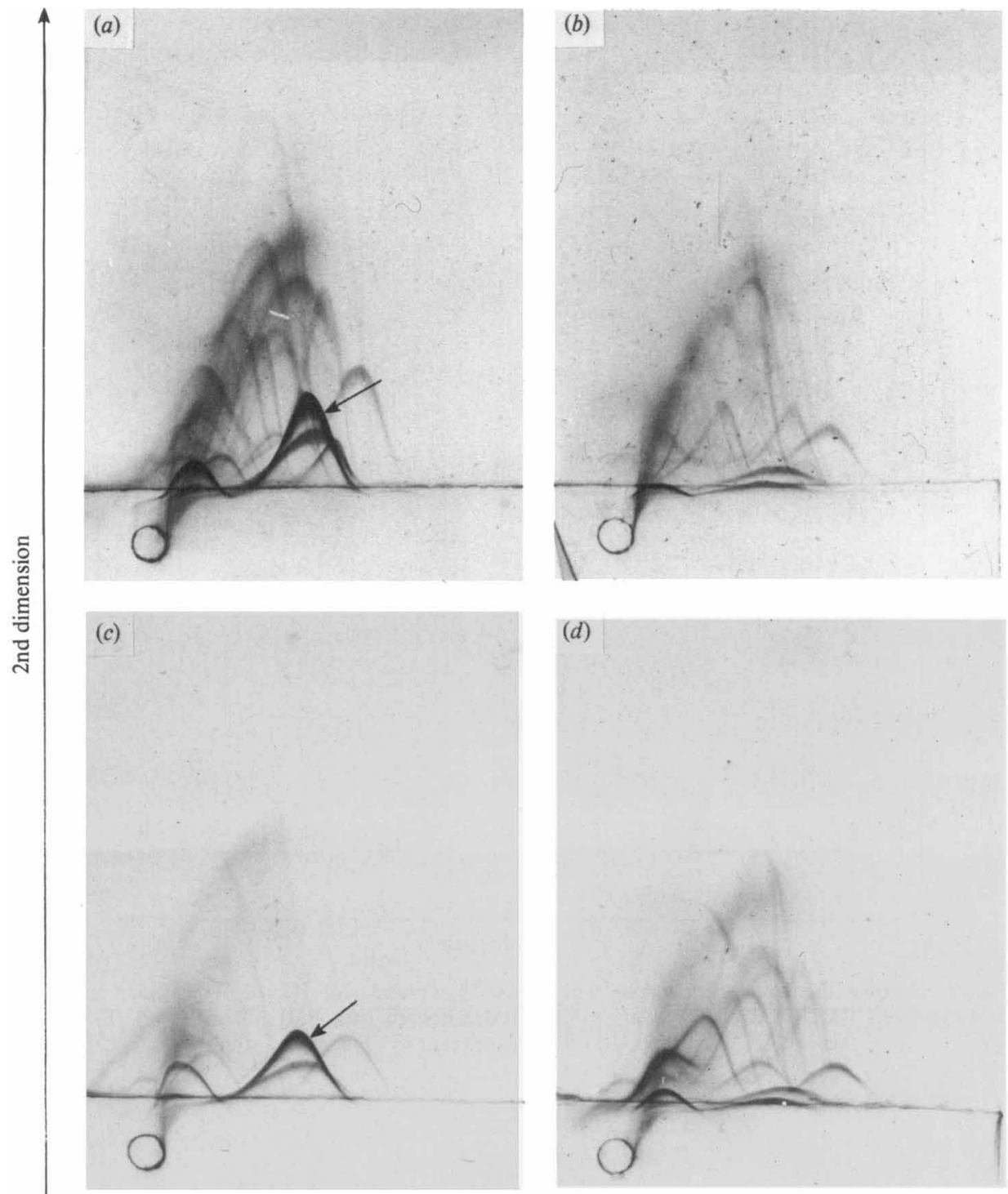

1st dimension

Fig. 4. Crossed immunoelectrophoresis of $V$. albo-atrum mycelial antigens against culture filtrate antisera. (a) Pooled PM and $(b)$ pooled FM against anti-PC/F. (c) Pooled PM and (d) pooled FM against anti-FC/F. Arrows indicate the precipitin lines produced by pooled PM, but not by pooled FM, with both antisera.

Comparison of RLIE patterns formed by pooled antigens with absorbed anti-PM and absorbed anti-FM (Fig. 7) showed that the major antigen precipitated with the culture filtrates was immunochemically identical to antigen ' 21 ' precipitated with the mycelial extracts. Furthermore, this antigen was undetectable by absorbed anti-FM. These results were consistent with the observations made with CIE patterns (Figs 3 and 4) that antibodies to an antigen present in pooled-PM, pooled $\mathrm{PC} / \mathrm{F}$ and pooled $\mathrm{FC} / \mathrm{F}$ were detectable using anti-PM but not when using anti-FM. 


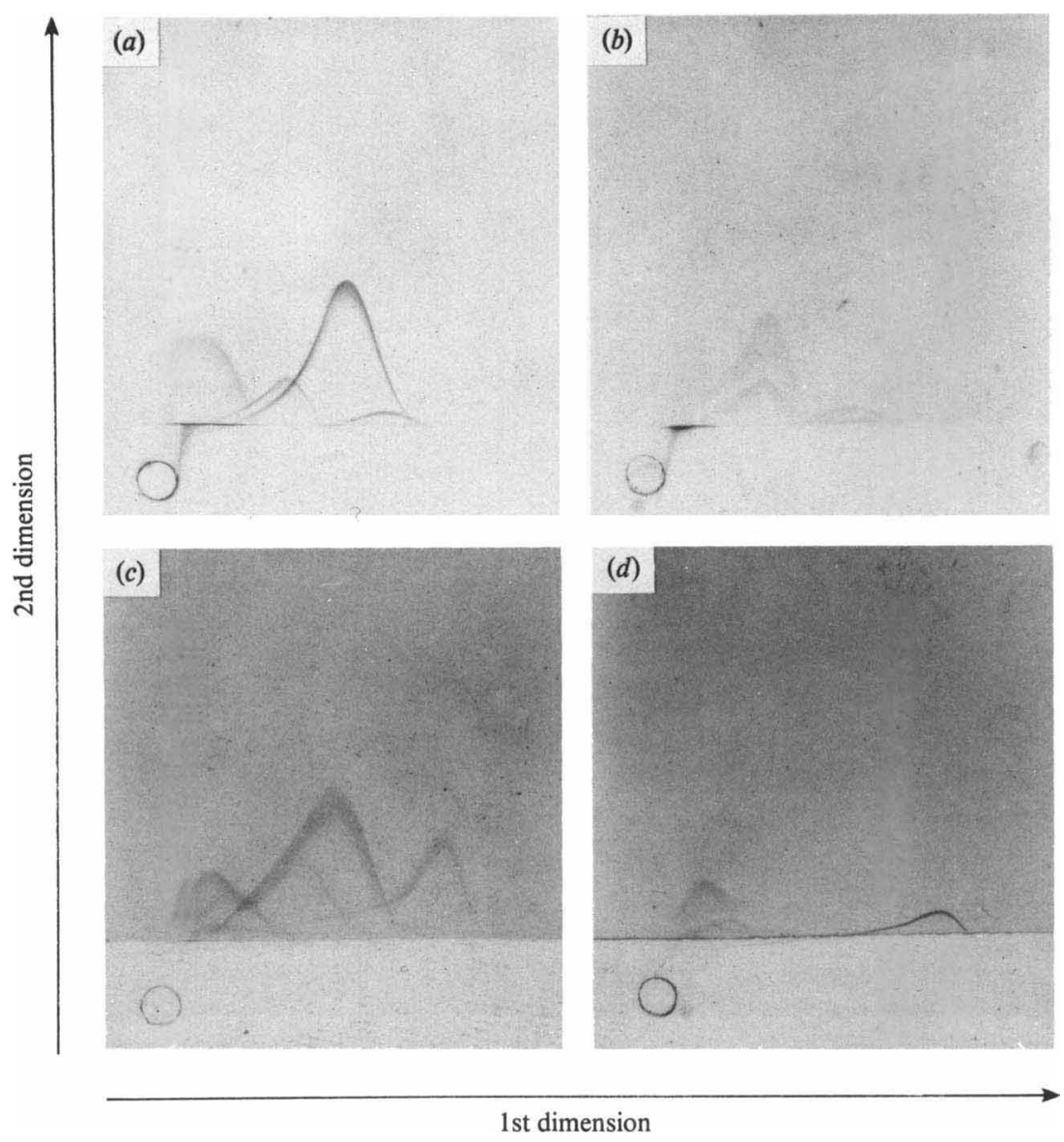

Fig. 5. Crossed immunoelectrophoresis with absorbed antisera. (a) Pooled PM against anti-PM absorbed with FM; $(b)$ pooled FM against anti-FM absorbed with $\mathrm{PM} ;(c)$ pooled $\mathrm{PC} / \mathrm{F}$ against anti-PC/F absorbed with $\mathrm{FC} / \mathrm{F} ;(d)$ pooled $\mathrm{FC} / \mathrm{F}$ against anti-FC/F absorbed with $\mathrm{PC} / \mathrm{F}$.

\section{DISCUSSION}

Mycelial and culture filtrate extracts from progressive isolates of $V$. albo-atrum were resolved into 29 and 22 antigens, respectively, by CIE, the number for the corresponding preparations from fluctuating isolates being 31 and 26, respectively. The culture filtrate antigens from the two types of isolate were shown to be identical by experiments with absorbed antisera. Similar experiments with the two mycelial extracts revealed that, except for one antigen, antigen ' 21 ', these also contained similar antigens.

On the basis of results described above (Figs 6 and 7), the $20 \mathrm{~V}$. albo-atrum isolates could be divided into three serological groups. In group 1, antigen ' 21 ' was detectable in substantial concentrations in both mycelial and culture filtrate preparations. In group 2 this antigen was absent, or nearly so, from both extracts; in group 3 it was present in low concentrations in the mycelial extracts, whereas in the culture filtrate preparations it varied from being undetectable to being present in substantial concentrations (though lower than those in group 1). Nine out of the 10 progressive isolates studied fall in group 1, so we suggest that this is the principal serotype of progressive isolates. Conversely, three fluctuating isolates (F1, F2 and F5) which failed to produce antigen ' 21 ' fall in group 2 , which forms one of the serotypes for fluctuating 

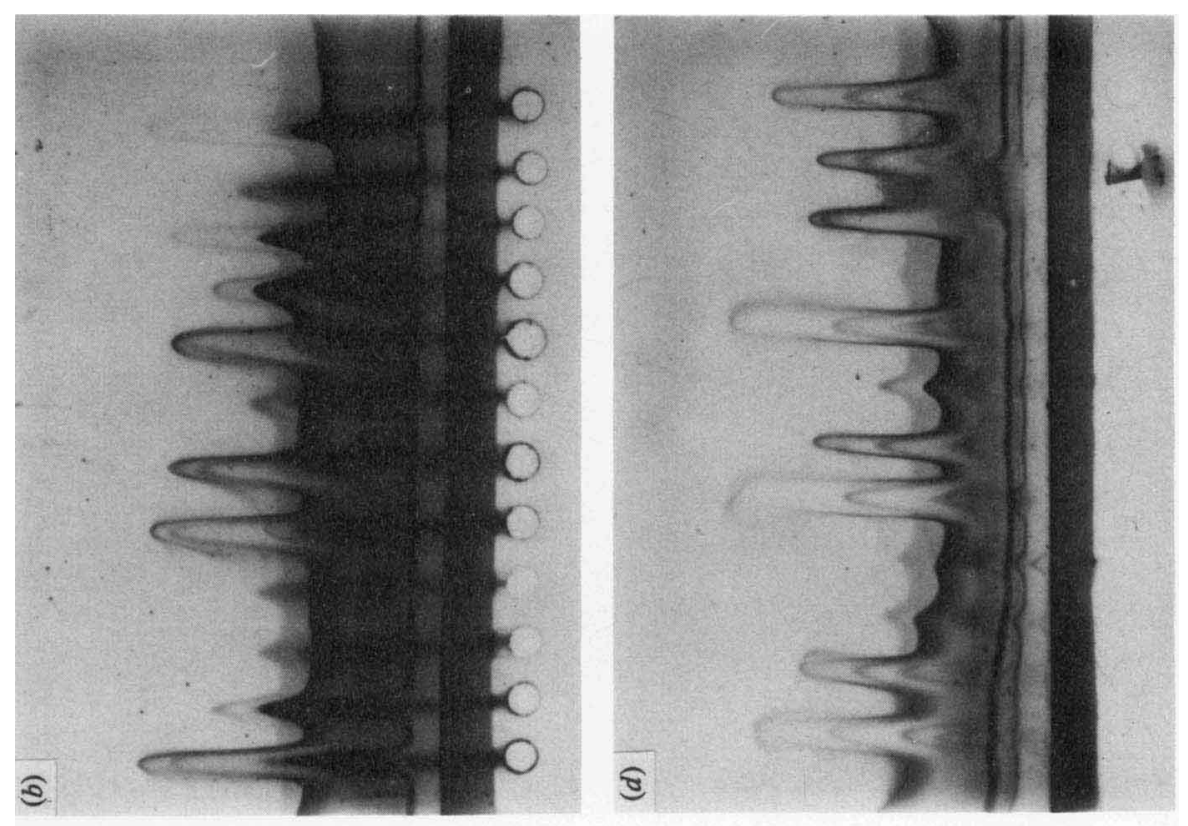

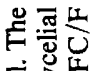

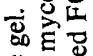

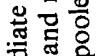
政这 㱐证

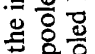
돌 $\sum_{i}$ 항맘 政 느음 उั丷 $\sum \overline{2}$ 红 部要 可 옹 형 要, $\sum_{i}$ 运些 安 의 訰 昰齿 氙志
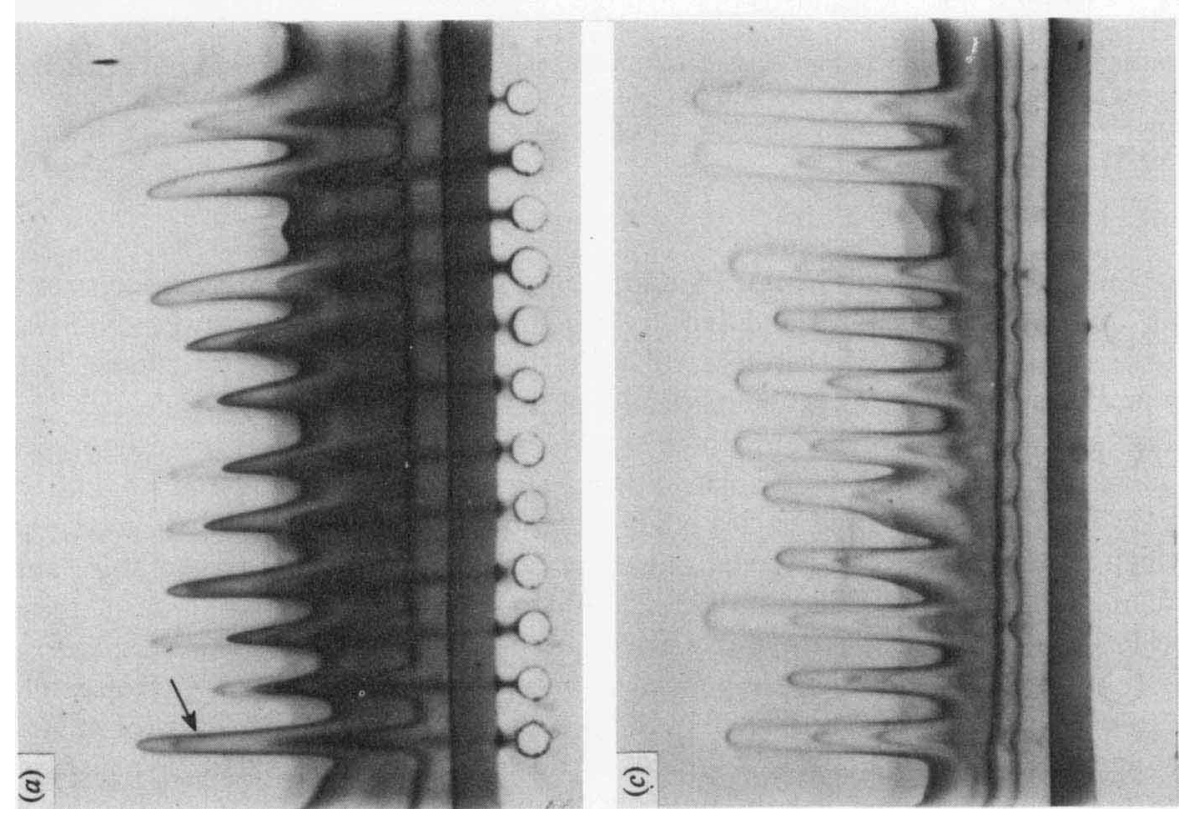

कू.

들

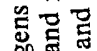

要这

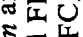
형 80 $8:$ ชิ $\sum_{1}$ 记 . 응 오ㅇㅛㅛ 응웅 E⿱乛龰 焉红 융 요 实正。 흘 荥웡 跑焉 통ㄴㄴ 象总

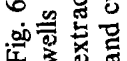




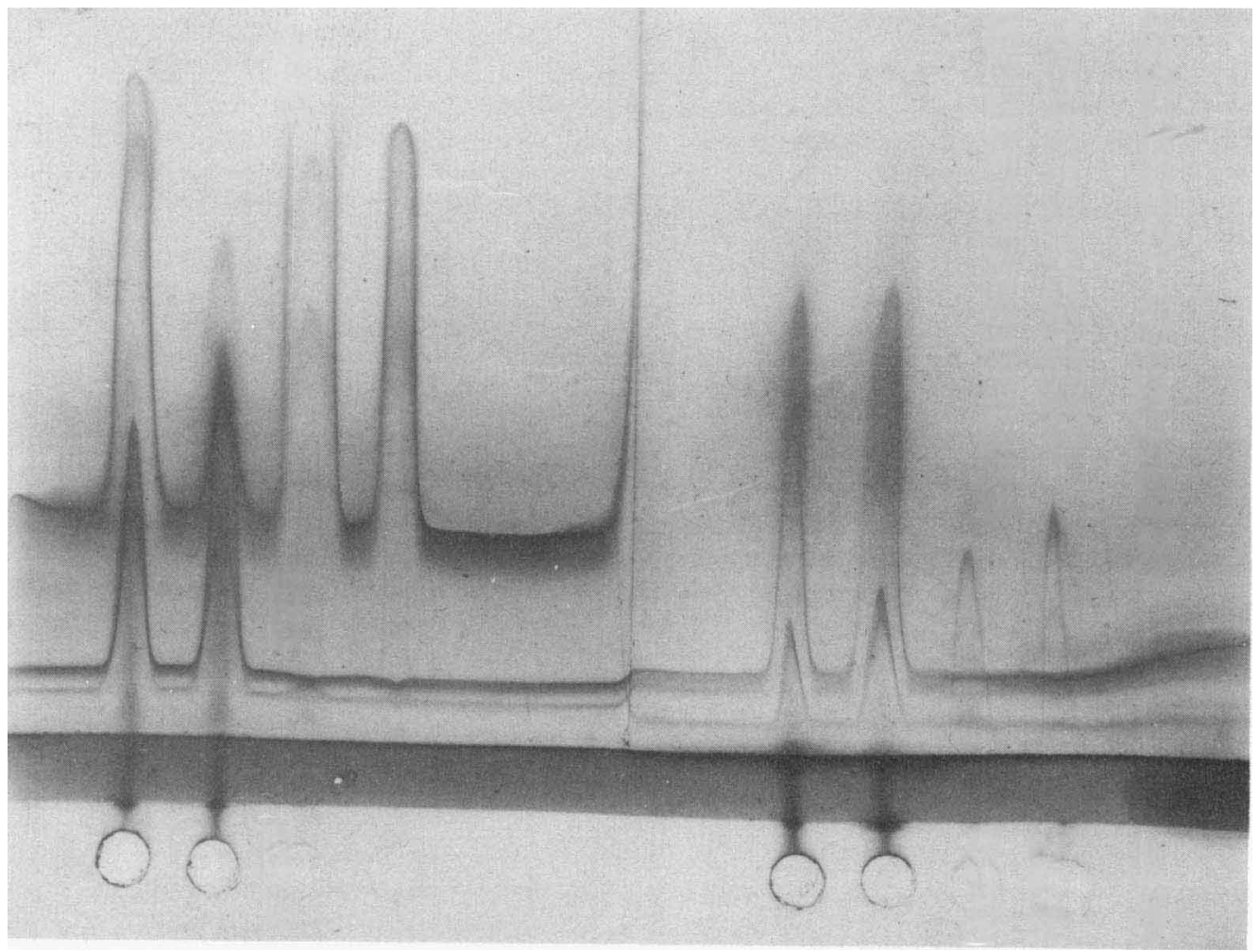

Fig. 7. Comparison, by rocket-line immunoelectrophoresis, of patterns produced by pooled $V$. albo-atrum antigens against absorbed mycelial antisera with pooled PM in the intermediate gel. The left half of the gel contained anti-PM absorbed with FM and the right half contained anti-FM absorbed with PM. The wells in both cases contained (from left to right) pooled PM, pooled FM, pooled PC/F and pooled $\mathrm{FC} / \mathrm{F}$.

isolates. Four fluctuating isolates (F7, F8, F9 and F10) fall in group 3, which characterizes a second group of fluctuating isolates and reflects a quantitative difference between the two types of isolate. It is suggested, therefore, that the high concentrations of antigen ' 21 ' produced by progressive isolates might be related to, or even account for, their virulence.

Of the 20 isolates studied, 16 fell in the three serotypes described above. If these serotypes are used to identify the remaining four isolates, then P8 falls in group 2, and F3, F4 and F6 fall in group 1 . The 20 isolates used in this study were identified by pathogenicity tests, the results of which can be influenced by environmental factors such as soil temperature and nitrogen availability (Sewell \& Wilson, 1973, 1974). It is conceivable that some of these isolates were misidentified. It is also possible that some isolates were either mixed cultures, containing both progressive and fluctuating isolates, or were heterokaryotic or heteroplasmic with respect to virulence. It is also feasible that the presence of fluctuating isolates (or nuclei) within potential progressive isolates might protect hop plants against the progressive disease. Such cross-protection with strains of V. albo-atrum has been reported in cotton (Schnathorst \& Mathre, 1966). If this is the case, then pathogenicity tests of hop plants infected with mixed cultures or heterokaryons might give results typical of an infection with a fluctuating isolate while serological techniques indicate a progressive isolate. Nevertheless, it should be possible to characterize such mixed cultures by purifying clones of each type of fungus and confirming the identity of the purified clones by both serological and pathogenicity tests. This work is now in progress. 
We are grateful to Dr D. Wiggell for the cultures of V. albo-atrum from hop and to the Ministry of Agriculture, Fisheries and Food for financial support.

\section{REFERENCES}

Evans. E. J. \& Framingham, E. E. (1979). Method of determining strain pathogenicity of Verticillium albo-atrum wilt of hops. Technical Bulletin, Ministry of Agriculture, Fisheries and Food, South Eastern Region.

HARboE, N. \& INGILD, A. (1973). Immunization, isolation of immunoglobulins, estimation of antibody titre. Scandinavian Journal of Immunology 2, Suppl. 1, 161-164.

HARrIs, R. V. (1927). A wilt disease of hops. Report East Malling Research Station for 1925, Suppl. II, 92.

IsSAC, I. \& KEYWORTH, W. G. (1948). Verticillium wilt of hop (Humulus lupulus). III. A study of the pathogenicity of isolates from fluctuating and from progressive outbreaks. Annals of Applied Biology 35, 243-249.

KEYworth, W. G. (1942). Verticillium wilt of the hop (Humulus lupulus). Annals of Applied Biology 29, 346-357.

KRøLL, J. (1973). Rocket-line immunoelectrophoresis. Scandinavian Journal of Immunology 2, Suppl. 1, 83-87.

LAURELl, C.-B. (1965). Antigen-antibody crossed electrophoresis. Analytical Biochemistry 10, 358361.

LAURELl, C.-B. (1966). Quantitative estimation of proteins by electrophoresis in agarose gel containing antibodies. Analytical Biochemistry 15, 45-52.

Ministry of Agriculture, Fisheries AND Food (1974). Advisory Leaflet No. 413.

Schnathorst, W. C. \& Mathre, D. E. (1966).
Cross-protection in cotton with strains of Verticillium albo-atrum. Phytopathology 56, 12041209.

Sewell, G. W. F. (1975). Environmental and fungal factors influencing Verticillium wilt of hop. Annals of Applied Biology 81, 443.

Sewell, G. W. F. \& Wilson, J. F. (1964). Verticillium wilt of hop: a summary of information and recommendations for control. Report East Malling Research Station for 1963, 193-198.

Sewell, G. W. F. \& Wilson, J. F. (1973). Hop wilt and soil temperature. Report East Malling Research Station for 1972, 207.

Sewell, G. W. F. \& Wilson, J. F. (1974). Hop wilt, soil temperature and nitrogen. Report East Malling Research Station for 1973, 203-204.

TAlboys, P. W. (1960). A culture medium aiding the identification of Verticillium albo-atrum and $V$. dahliae. Plant Pathology 9, 57-58.

TalboYs, P. W. \& Wilson, J. F. (1954). A method for determining the pathogenicity of strains of Verticillium albo-atrum isolates from hop. Report East Malling Research Station for 1953, 158-161.

VoGEL, H. J. (1956). A convenient growth medium for Neurospora. Microbial Genetics Bulletin 13, 42-43.

Webb, H. M., Gafoor, A. \& Heale, J. B. (1972). Protein and enzyme patterns in strains of Verticillium. Transactions of the British Mycological Society 59, 393-402.

WEEKE, B. (1973). Crossed immunoelectrophoresis. Scandinavian Journal of Immunology 2, Suppl. 1, 47-56. 